\title{
Aspects of Entrepreneurial Opportunities in the Field of Construction, Case Study: The Tehran Metropolitan Area
}

\section{Esfandabadi $\mathrm{HM}^{1 *}$, Esfandabadi $\mathrm{AM}^{2}$ and Mousavi $\mathrm{SF}^{3}$}

${ }^{1}$ Department of Economics and Sociology, University of Tehran, North Karegar Ave, Tehran, Iran ${ }^{2}$ Payame Noor University, Iran

${ }^{3}$ Department of Entrepreneurship, University of Tehran, North Karegar Ave, Tehran, Iran

\begin{abstract}
The present paper aims to investigate some aspects of entrepreneurial opportunities among the actors in the construction industry. These aspects include entrepreneurial alertness, financial incentives, prior knowledge and information asymmetry.

The research methodology according to the purpose is applied and data collection is descriptive - survey. The research population includes 333 active members of Employers' Association and construction, equipment and facilities companies. Using the Cochran's formula, 179 individuals were selected through stratified random sampling method as the statistical population. The questionnaire has been used as the data collection instrument.

The results show that, on a descending order, the aspects of financial incentives followed by prior knowledge/ experience and entrepreneurial alertness are important in identifying entrepreneurial opportunities. Information asymmetry was lowest in rank among the four aspects of entrepreneurial opportunity identification in the construction industry in the city of Tehran.
\end{abstract}

Keywords: Entrepreneurial opportunity identification; Entrepreneurial alertness; Financial incentives; Information asymmetry; Construction industry

\section{Introduction}

The industry of construction is a main job in Iran and it is a job high income at present. Some jobs (high income) of Construction are including: The architect, designer, Seller Construction equipment and Construction materials production. The built environment is typically a country's most important asset, both economically and socially [1]. For advanced countries around 95\% of people work in the built environment, where they generate around $80 \%$ of GDP [1].

The construction is a network of builder individual at present. At words, Construction has an economics entrepreneurial that they have an expertise network of the construction uniquely.

One of the key factors in urban life revolves around housing. The housing is the foremost factor that sustains and nurtures civilizations and social cultures, resulting in the improvement of housing, municipal services, social stability, environmental conditions, and social participation.

Thus, theentrepreneurial of Construction have a variousopportunity that they try to engage their network exactly. The opportunities of construction are including: partnership on Construction, Construction sale and etc. which is the culmination of the individual's performance and the external environment. Opportunity is a dynamic construct that ebbs and flows according to a continually changing environment [2]. In other words, personal factors and social ties play a crucial role in the identification of entrepreneurial opportunities. Ardichvili et al. [3] argues that opportunities, in the initial stages of formation, are the market's obscure needs or resources or capacities that have not been exploited well.

The ability to recognize and choose the right opportunities is considered as the most important characteristic for a successful entrepreneur in launching a start-up business. Opportunity identification in the field of entrepreneurship has been recognized as the key entrepreneurial process [4]. Development of ideas occurs when the entrepreneur has an interaction with the environment.

During times of recession or slump, the housing sector is one of the sectors that could help the government offset the decline in other sectors. In Iran, approximately 9 to 12 percent of the employed work in the housing sector (Statistical Center of Iran website, 2012) ${ }^{1}$. At other words, Identification of entrepreneurial opportunities in this sector could increase youth employment and rate of marriage which could in turn have social and psychological effects on the society.

Considering the importance of housing and its impact on other economic and social areas, it is very important to recognize existing opportunities in this area. However, before anything else, it is necessary to examine each aspect of entrepreneurial opportunity identification in the field of construction.

Based on the previous research, numerous aspects have been identified for entrepreneurial opportunities and how to recognize them such as entrepreneurial alertness, cognitive features, training, creativity, financial incentives, prior knowledge/experience, social networks and entrepreneurial index. Each of the aforementioned aspects could influence the process of entrepreneurial opportunity identification in the field of construction. In the present paper, four

'https://www.amar.org.ir/english

*Corresponding author: Esfandabadi HM, Department of Economics and Sociology, University of Tehran, North Karegar Ave, Tehran, Iran, Tel: (+9821)66405047; E-mail: hme.moghimi30@gmail.com

Recieved November 02, 2017; Accepted May 21, 2018; Published May 29, 2018

Citation: Esfandabadi HM, Esfandabadi AM, Mousavi SF (2018) Aspects of Entrepreneurial Opportunities in the Field of Construction, Case Study: The Tehran Metropolitan Area. J Entrepren Organiz Manag 7: 239. doi: 10.4172/2169026X.1000239

Copyright: () 2018 Esfandabadi HM, et al. This is an open-access article distributed under the terms of the Creative Commons Attribution License, which permits unrestricted use, distribution, and reproduction in any medium, provided the original author and source are credited. 
components of entrepreneurial alertness, creativity, financial incentives and information asymmetry have been considered for the construction industry. The main object of paper is "Aspects of entrepreneurial opportunities in the Field of Construction".

\section{Literature Review}

\section{Definitions}

The entrepreneurial opportunity is difficult to define as it can mean different things to different people [5]. Situations in which new goods, services, raw materials, and organizing processes can be introduced and sold at greater than their cost of production Entrepreneurial opportunities require the discovery of new means ends relationships [6]. Individuals may recognize opportunities to start ventures because they have superior access to information due to differentiated search behavior or social networks [7].

Opportunity identification is the first step in the entrepreneurial process. An opportunity can be exploited when the entrepreneur is able to identify opportunities and recognize their importance (value) for their business. Since one needs to be able to identify opportunities in order to become an entrepreneur, it is crucial to acquire/hone the skill of identifying opportunities to increase one's chances of becoming an entrepreneur [8].

There are two opposing views regarding opportunities. One view argues that opportunities are discovered while the other view argues that they are created [5,9]. According to Shane and Venkatarman [4] the majority of researches in the field of recognizing the opportunity should be focused on the point of how to discover and exploit from opportunities in order to create and give goods and services and why only some of individuals may discover such opportunities $[4,10]$.

\section{Background Research}

The table below outlines some of the previous research on opportunity identification and entrepreneurial alertness, prior knowledge/experience, financial incentives and information asymmetry (Table 1 ).

The pervious researches are very high on the entrepreneurship opportunity at present. Aspects of entrepreneurial opportunities in the field of construction are a different topic that it has a few researches at present. The researches have a research monopoly on the entrepreneurial opportunities. The entrepreneurial opportunities have different areas among researches.

\begin{tabular}{|l|l|l|}
\hline Name & Year & Subject \\
\hline Shane & $(2000)$ & $\begin{array}{l}\text { The relationship between prior knowledge and } \\
\text { opportunity recognition. }\end{array}$ \\
\hline Gaglio and Katz & $(2001)$ & $\begin{array}{l}\text { Entrepreneurial alertness, the psychological basis } \\
\text { of opportunity identification. }\end{array}$ \\
\hline Ardichvili et al. & $(2003)$ & $\begin{array}{l}\text { Reviewing the process of opportunity identification } \\
\text { and development. }\end{array}$ \\
\hline Dyer et al. & $(2008)$ & $\begin{array}{l}\text { Entrepreneur Behaviors, opportunity recognition } \\
\text { and the origins of innovation ventures. }\end{array}$ \\
\hline Abessi et al. & $(2015)$ & $\begin{array}{l}\text { Recognition of social dimensions of entrepreneurial } \\
\text { opportunities in the field of animal Wild life. }\end{array}$ \\
\hline $\begin{array}{l}\text { Esfandabadi } \\
\text { et al. }\end{array}$ & (2016) & $\begin{array}{l}\text { The Effect of Social Capital on Opportunity } \\
\text { Recognition in Entrepreneurs as Mediated by the } \\
\text { Social Network. }\end{array}$ \\
\hline
\end{tabular}

\section{Results}

Entrepreneurs discover opportunities because of the information they already have which comes from prior knowledge.

A model on how to gauge entrepreneurial alertness performance in the opportunity identification process.

Proposed a model composed of the main factors of entrepreneurial opportunity identification process (i.e. entrepreneurial alertness, prior knowledge, social networks, personal characteristics such as risk-taking, optimism, self-efficacy and creativity and the type of opportunity) and determined the relationship between them.

Innovative entrepreneurs are less susceptible to the status quo bias and engage in these information-seeking behaviors with a motivation to change the status quo. of norms and confidence are ranked at next positions in terms of preferences.

The results show that social capital positively influences opportunity recognition with relational social capital delivering the most impact.

Table 1: A summary of the previous research on opportunity identification and entrepreneurial alertness, prior knowledge/experience, financial incentives and information asymmetry. 
and benefits, and as such are the motivating forces behind economic behavior [14]. There are three ways to create financial incentives in the field of construction [1]:

1. Share of savings incentives, where cost savings are shared between the client and the contractor based on an agreed formula.

2. Schedule incentives, where a premium is offered to the contractor for the early completion of the project.

3. Technical performance bonuses for meeting performance targets, other than cost and schedule. A performance bonus arrangement can be applied to a wide range of performance areas such as quality and functionality.

$\mathrm{He}$ argues that a construction contractor's (agent's) output (or performance) is a function of factors within their control (ability and motivation) and external factors outside their control (environment) [1].

Not only do financial incentives in the construction industry increase individuals' motivation on the personal and organizational level, but also enhances the unit's motivation across the project team and contract teams. As a result, the second research question would be as follows:

Question 2: What is the state of the financial incentives measure in the identification of entrepreneurial opportunities in the construction industry in the city of Tehran?

\section{Information asymmetry}

In his studies, Venkataraman [16] reflects on the role of dispersed knowledge in opportunity identification which was originally introduced by Hayek [17]. In his opinion, because of having knowledge in different areas, entrepreneurs are able to recognize profitable opportunities when others cannot access those opportunities due to the lack of information.

Information asymmetry occurs when individuals have different amounts of information in terms of resources, markets and opportunities. Employing additional resources and information leverages which provide some advantages for them, some entrepreneurs invest on information asymmetry. These entrepreneurs are more likely to engage in the opportunity discovery and identification process
[16,18]. Venkataraman and Shane [4] examined the role of information asymmetry in exploiting opportunities. Therefore, the third research question would be as follows:

Question 3: What is the state of information asymmetry measure in identification of entrepreneurial opportunities in the construction industry in the city of Tehran?

\section{Prior knowledge}

Much of the previous research in the field of entrepreneurship has supported the role of prior knowledge/experience in gathering information from limited resources and thus increasing the likelihood of business opportunity identification $[19,20]$. Also, Shane [21] developed theories that support the importance of prior knowledge in the opportunity identification process (Figure 1).

Prior knowledge helps individuals in identifying opportunities and is classified into three categories: having market knowledge, having knowledge on how to serve the market, and having enough knowledge about the needs and problems of customers [21].

Based on the above, the third research question would be as follows:

Question 4: What is the state of the prior knowledge/experience measure in entrepreneurial opportunities identification in the construction industry in the city of Tehran?

\section{Methodology}

\section{Method}

The research methodology according to the purpose is applied and data collection is descriptive - survey. At words, the paper employs a quantitative approach for data collection and also adopts an empirical approach in terms of purpose. The data collection instrument consists of a 5-Lickert scale questionnaire which has been used to assess the views of individuals toward entrepreneurial opportunity identification [22].

\section{Statistical population, sample size and sampling method}

The statistical population of the research includes the active member firms of the Employers Association and construction, equipment and facilities companies amounting altogether to 333 firms. Based on the Cochran's formula and calculating a 5\% error level, 179 individuals

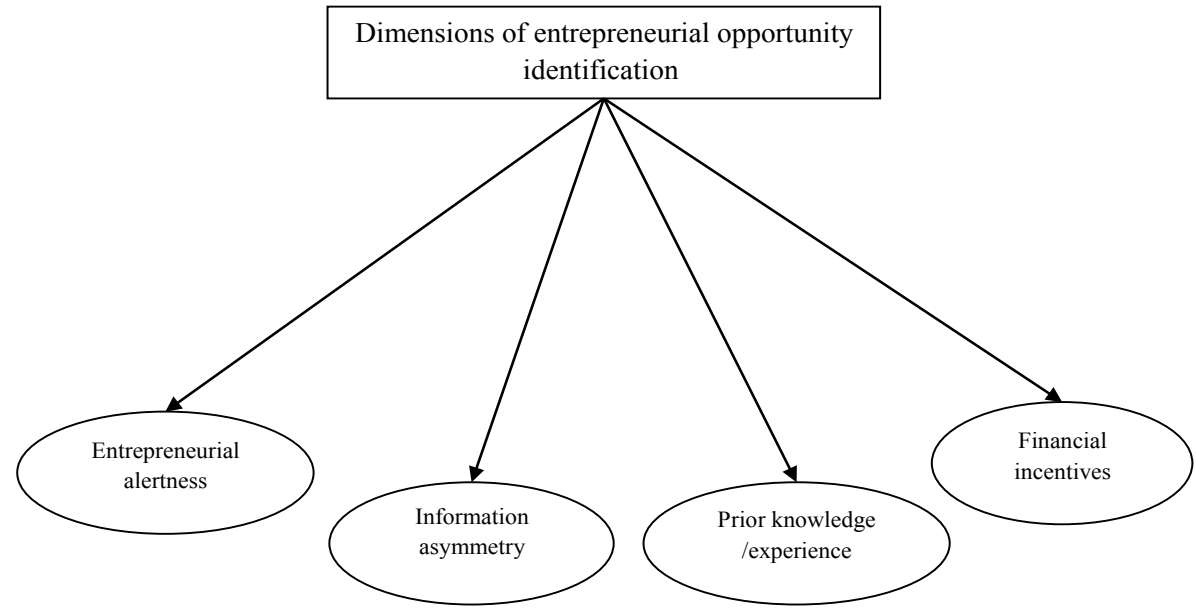

Figure 1: Theoretical framework of the research. 
were selected through a stratified simple random sampling method as the research sample. The questionnaire instrument has been used for data collection [23].

\section{Data Collection Method}

In this paper, the library research method has been used for the investigation of the theoretical studies and the previous research. After completing the theoretical framework, a questionnaire with 20 questions was prepared consistent with the 1 to 5 lickert scale (totally agree to total disagree). There are four indices in this section as illustrated in the table below (Table 2)

\section{Reliability and Validity of the Measurement Instrument}

Validity: the validity of the designed questionnaire content was determined by a number of experts informed within the research subject. Thus, it is needless to say that the validity of the content relied on the judgment of the experts. Therefore, in order to ascertain the validity of the content, the designed questionnaire was examined by a number of experts. After verifying the accuracy of the content the questionnaire was distributed among the study population $[24,25]$.

Reliability: the reliability coefficient indicates how the measurement instruments could measure the determinable constant features or the temporal features. Using Cronbach's alpha the following reliability values were obtained for the indices (Table 3 ).

\section{Data Analysis}

The SPSS $_{22}$ software was used for the analysis of the data. First, the descriptive data were examined which included the frequencies, percentages, means, standard deviation, and the minimum and maximum values of the indicators And then, for the inferential statistics, procedures such as the one-sample $t$ test were undertaken in order to assess the meaningfulness of each variable and to examine the utility of the indicators for the study sample i.e., the active construction companies in the city of Tehran with over 5 years of experience. Later, the Friedman's test was conducted in order to rank and prioritize the research indicators $[26,27]$.

\section{Results}

\section{Description of indicators}

Table 4 presents the descriptive statistics on each index of the entrepreneurial opportunity identification including the mean, standard deviation, and the minimum and maximum of indices. Prior knowledge/ experience and entrepreneurial alertness have the highest means and the financial incentives index and information asymmetry have lower means.

\begin{tabular}{|c|c|}
\hline Indicators & Questions \\
\hline Entrepreneurial Alertness & $1-5$ \\
\hline Prior Knowledge/Experience & $6-10$ \\
\hline Financial Incentives & $11-15$ \\
\hline Information Asymmetry & $16-20$ \\
\hline
\end{tabular}

Table 2: Research indicators.

\begin{tabular}{|c|c|c|}
\hline Indicators & $\begin{array}{c}\text { Number of } \\
\text { questions }\end{array}$ & $\begin{array}{c}\text { Cronbach's } \\
\text { alpha }\end{array}$ \\
\hline Entrepreneurial alertness & 5 & $0 / 85$ \\
\hline Prior knowledge/experience & 5 & $0 / 86$ \\
\hline Financial incentives & 5 & $0 / 88$ \\
\hline Information asymmetry & 5 & $0 / 85$ \\
\hline
\end{tabular}

Table 3: Cronbach's alpha of the research indicators.

\section{Testing research questions}

The test of research questions based on the state of the dimensions of entrepreneurial opportunity identification in the construction industry in the city of Tehran (Table 5).

Table 4 represents the state of entrepreneurial opportunity identification among the construction industry active companies with over than 5 years of experience. Therefore, according to the significance level obtained from the one-sample t-test, all the research questions were supported. In the same vein, the obtained significance level (i.e. 0.000 ) is smaller than 0.01 which indicates that all the dimensions of entrepreneurial opportunity identification are confirmed with a $99 \%$ level of confidence. On the other hand, the values that were obtained from the one-sample t-test suggest the utility of each dimension of the entrepreneurial opportunity identification process. Entrepreneurial alertness has the highest utility and information asymmetry has the lowest utility in comparison with the other indices of the entrepreneurial opportunity identification in the construction industry.

\section{Ranking of indicators}

Table 6 illustrates the importance of each indicators of entrepreneurial opportunity identification in the construction industry. Prior knowledge/experience has the highest rank and hence the highest priority among all the existing indices. Having a lower average, the entrepreneurial alertness index comes second with regard to importance. The financial incentives and information asymmetry indices have lesser importance than the rest.

\section{Discussion and Conclusion}

The construction industry is one of the most challenging industries in Iran. Paying more attention to this industry and advancing entrepreneurship in this area could significantly impact the economy, employment, and social welfare.

Entrepreneurship will flourish only when entrepreneurs are able to properly identify the existing opportunities in the environment and exploit them in the right time. This requires a proper understanding of entrepreneurial opportunities.

\begin{tabular}{|c|c|c|c|}
\hline Indicators & Frequency & Mean & SD \\
\hline Financial incentives & 179 & $11 / 30$ & $3 / 7$ \\
\hline Prior knowledge/experience & 179 & $11 / 60$ & $3 / 9$ \\
\hline Entrepreneurial alertness & 179 & $11 / 60$ & $3 / 5$ \\
\hline Information asymmetry & 179 & $10 / 60$ & $3 / 9$ \\
\hline
\end{tabular}

Table 4: Descriptive statistics of the research indices in terms of means and standard deviation.

\begin{tabular}{|c|c|c|}
\hline Indicators & t value & Significance level \\
\hline Financial incentives & $31 / 75$ & $0 / 000$ \\
\hline Prior knowledge/experience & $31 / 26$ & $0 / 000$ \\
\hline Entrepreneurial alertness & $32 / 59$ & $0 / 000$ \\
\hline Information asymmetry & $27 / 66$ & $0 / 000$ \\
\hline
\end{tabular}

Table 5: The test of research questions based on the state of the dimensions of entrepreneurial opportunity identification in the construction industry in the city of Tehran.

\begin{tabular}{|c|c|c|}
\hline Indicators & Value of rank & Rank \\
\hline Prior knowledge/experience & $2 / 86$ & 1 \\
\hline Entrepreneurial alertness & $2 / 49$ & 2 \\
\hline Financial incentives & $2 / 42$ & 3 \\
\hline Information asymmetry & $2 / 23$ & 4 \\
\hline
\end{tabular}

Table 6: Ranking of the entrepreneurial opportunity identification indicators using the Friedman's test. 
The present paper attempts to assess the state of four measures from the various existing measures of entrepreneurial opportunity identification in the active construction industry companies in the city of Tehran. The purpose is to identify and rank some of the entrepreneurial opportunity identification dimensions in the said industry. Construction companies need to acquire a better understanding of these dimensions and invest on them so that they may be able to identify or create new entrepreneurial opportunities.

Based on the research results, prior knowledge/experience was recognized as the most important factor in the entrepreneurial opportunity identification in the construction industry. Warren The possession of prior experience in the construction industry and accordingly producing the right reaction based on market change could significantly influence the entrepreneurial opportunity identification in this field.

Entrepreneurial alertness is the second most important factor in identifying entrepreneurial opportunities. It is a process which helps entrepreneurs become aware of environmental change, opportunities and existing potentials. Discovery of new opportunities is directly related with entrepreneurial alertness, skills and entrepreneurial vision $[12,13]$.

Entrepreneurial alertness and patterns help people organize information from different knowledge bases for the purpose of creating new opportunities [8]. Entrepreneurial alertness could also significantly help entrepreneurs and active participants in the construction industry in predicting future changes and making shrewd judgments.

Of all the four examined indices, the financial incentives index came third in rankings. Financial incentives help increase efficiency and productivity of construction projects by increasing motivation for delivering more conscientious and thorough performance.

Not only do financial incentives help increase motivation in entrepreneurs for searching and discovering entrepreneurial opportunities, but also increase the unit's motivation across the entire project team and contract teams.

Information asymmetry is the fourth important factor in identifying entrepreneurial opportunities in the construction industry. Entrepreneurs that invest on information asymmetry are more likely to engage in the process of "discovery and identification" of opportunities by help of information leverages and complementary resources which provide them with advantages $[16,18]$.

\section{Recommendations}

Based on the research results, we offer the following solutions that could enhance the identification and exploitation of existing entrepreneurial opportunities in the construction industry:

- Compiling the experiences of the veterans in this area and transferring them to other actors.

- Offering financial incentives provided by the government to discover efficient solutions and opportunities in the construction industry.

\section{References}

1. Rose TM, Manley K (2011) Motivation toward financial incentive goals on construction projects. J Bus Res 64: 765-773.

2. Hunter M (2013) A Typology of Entrepreneurial Opportunity. Economics, Management, and Financial Markets 8: 128-166.
3. Ardichvili A, Cardozo R, Ray S (2003) A Theory of Entrepreneurial Opportunity Identification and Development. J Bus Venturing 18: 105-123.

4. Shane S, Venkataraman S (2000) The Promise of Entrepreneurship as a Field Entrepreneurship. Acad Manage Rev 25: 217-226.

5. Lim WL, Xavier RS (2015) Opportunity Recognition Framework: Exploring the Technology Entrepreneurs. Am J Econ 5: 105-111.

6. Shane S (2012) Reflections on the 2010 AMR decade award: delivering on the promise of entrepreneurship as a field of research. Acad Manage Rev 37: 10-20.

7. Dyer JH, Gregersen H, Christensen C (2008) Entrepreneur Behaviors, opportunity recognition and the origins of innovation ventures. Strateg Entrep J 2: 317-338.

8. Gaglio CM, Katz J (2001) The psychological basis of opportunity identification: Entrepreneurial alertness. Small Bus Econ 16: 95-111.

9. Alvarez SA, Barney JB (2004) Organizing Rent Generation and Appropriation: Toward a Theory of the Entrepreneurial Firm. J Bus Venturing 19: 621-635.

10. Razavi SM, Moghimi Esfandabadi H, Mousavi SF, Shahmiri N (2014) A survey of impact of social environment on entrepreneurial opportunities of plant Wild life (A Case Study in Abadeh Region). Asian Journal of Research in Business Economics and Management 4: 224-234.

11. Kirzner IM (1973) Competition and entrepreneurship. University of Chicago Press.

12. Kirzner IM (1999) Entrepreneurial Discovery and the Competitive Market Process: An Austrian Approach. J Econ Lit 35: 60-85.

13. Kaish S, Gilad B (1991) Characteristics of Opportunities Search of Entrepreneurs verses Executives: Sources, Interests and General Alertness. J Bus Venturing 6: 45-61.

14. McCaffrey M (2013) On the Theory of Entrepreneurial Incentives and Alertness Entrep Theory Pract 38: 891-911.

15. Ray S, Cardozo R (1996) Sensitivity and Creativity in Entrepreneurial Opportunity Recognition: A Framework for Empirical Investigation. Global Entrepreneurship Research Conference.

16. Venkataraman S (1997) The distinctive domain of entrepreneurship research An editor's perspective. Advances in entrepreneurship, firm emergence, and growth 3: 119-138

17. Hayek FA (1945) The use of knowledge in society. Am Econ Rev 35: 519-530.

18. Sarasvathy SD, Dew N, Velamuri SR, Venkataraman S (2003) Three views of entrepreneurial opportunity. Kluwer Academic Press pp: 141-160.

19. Fiet JO (2007) A prescriptive analysis of search and discovery. J Manag Stud 44: 592-611.

20. Fiet JO, Patel PC (2008) Entrepreneurial discovery as constrained, systematic search. Small Bus Econ 30: 215-229.

21. Shane S (2003) A General Theory of Entrepreneurship: The IndividualOpportunity Nexus. Nothampton MA : Edward Elgar.

22. Khadijeh A, Mostafe RS, Mohgimi EH, Neda S (2015) Recognition of social dimensions of entrepreneurial opportunities in the field of animal Wild life (A Case Study in Abadeh Town). Asian Journal of Research in Social Science Humanities 5: $116-126$.

23. Bruke A (2011) The Entrepreneurship Enabling Role of Freelancers: Theory with Evidence from the Construction Industry. International Review of Entrepreneurship.

24. Esfandabadi HM, Farsi JY, Mobaraki MH, Esfandabadi ARM (2016) The Effect of Social Capital on Opportunity Recognition in Entrepreneurs as Mediated by the Social Network: A Case of Managers in the Science and Technology Park of the University of Tehran. AJBMR 6: 199.

25. Hulbert B, Gilmore A, Carson D (2012) Sources of opportunities used by growth minded owner managers of small and medium sized enterprises. Int Bus Rev 22: 293-303

26. Shane S (2000) Prior Knowledge and the Discovery of Entrepreneurial Opportunities. Organ Sci 11: 448-469.

27. Tang J, Kacmar K, Busenitz L (2012) Entrepreneurial alertness in the pursuit of new opportunities. J Bus Venturing 27: 77-94. 